\title{
The perception of patients of the professionalism of dental students at a Tertiary Oral Health Centre, South Africa
}

SADJ November 2018, Vol. 73 No. 10 p612 - p616

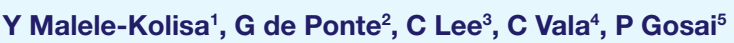

\section{ABSTRACT}

Introduction

Professionalism in the healthcare setting refers to the standards a patient can expect from his/her healthcare practitioner (HCP). Appearance, behaviour, attitude and communication skills are all attributes of professionalism.

\section{Aim}

To assess the perceptions of patients of the professionalism of oral health students at an South African Tertiary Oral Health Care Centre (SA-OHC).

\section{Methods}

A cross-sectional, analytical study was conducted using an interviewer-administered questionnaire. Photographs depicting various dress codes were included in the questionnaire given to patients.

\section{Results}

A total of 118 patients with a mean age of 44 years (sd-18.16) were interviewed. The majority $(n=76 ; 65 \%)$ were previously booked patients; $72 \%$ female; $53 \%$ black; and $85 \%$ in the earning category of up to $R 3000 \mathrm{p} / \mathrm{m}$. The Cronbach alpha score was good at 0.7 . 96\% of patients agreed that the students looked professional in lab coats (79.5\%), then surgical gowns (55.9\%) and thirdly scrubs (50.9\%) although not in formal wear $(66 \%$. In terms of communication skills and behaviour, students were highly rated (91\%-99\%). Payment classification, education level and gender influenced patient perceptions $(p<0.05)$.

\section{Conclusion}

Students were highly regarded by patients generally, and patients perceived lab coats and surgical gowns to be more professional than formal garb.

\footnotetext{
Author affiliations:

1. Yolanda Malele-Kolisa, BDS MPH, MDent (Community Dentistry), Department of Health, Head, Clinical Unit, Department of Community Dentistry, School of Oral Health Sciences, University of the Witwatersrand, Johannesburg, South Africa.

2. *Genevieve de Ponte, BDS

3. *Catherine Lee, BDS

4. ${ }^{*} \mathrm{C}$. Vala, MSc, BDS.

*P. Gosai, MSc, BDS.

*Community Dentists 2018

Corresponding author: Yolanda Malele-Kolisa

Community Dentistry, University of the Witwatersrand, Johannesburg,

South Africa. Tel: +27 (0)83780 0907 Email: yolanda.kolisa@wits.ac.za
}

\author{
ACRONYMS \\ HCP: Healthcare Practitioner \\ SA-OHC: $\quad$ South African Tertiary Oral \\ Health Care Centre
}

\section{INTRODUCTION}

Professionalism in health care can be defined as "the standard to which a patient can and should expect from their health care practitioner". ${ }^{1}$ The Health Professions Council of South Africa (HPCSA) considers professionalism to be "a relationship of mutual trust between patients and health care practitioners". ${ }^{2}$ Professionalism also entails the application of scientific knowledge to clinical skill, communication skills between patients, staff and the practitioner and maintaining current and new relationships built on trust with the patient. ${ }^{3,4}$ Professionalism is a complex overlap between behaviour, skill, communication and appearance.

Professionalism in dentistry is important because the physical appearance and behaviour of the dentist often have an effect on the first impression of a patient and on subsequent interpersonal relationships. ${ }^{5}$ First impressions are rendered even more important in the dental setting due to the anxiety, fear and vulnerability of patients. ${ }^{6}$

There are various studies in the literature that have assessed professionalism across many professions, especially in the field of Health Science. . $^{3,6,7}$ However, the majority of these studies have been performed in the developed world. , $^{3,7-9}$ Published literature in South Africa concerning professionalism is centred on the medical profession.

The physical appearance of health-care practitioners is vital in terms of first impressions, in developing rapport with patients and influencing their willingness to disclose personal details. ${ }^{10}$ Professionalism is therefore an "image that will promote a successful relationship with the patient". ${ }^{3}$ That image is a result of first impressions, based the physical appearance of the professional. ${ }^{3,7}$ Furnham et al (2014) showed that for the development of a relationship, their respondents preferred a white coat or formal suit to informal dressing styles. ${ }^{7}$ These authors attributed the rapport to the fact that more formal attire gave an "air of credibility". Deshmukh and colleagues (2013) stated that white lab coats have become a symbol of authority. The study also found that patients had a higher preference for white lab coats - without necessarily considering the dentists themselves. ${ }^{8}$ Older age (>60 years) was associated with a preference for dentists 
wearing the lab coats. ${ }^{8}$ In contrast, Mistry and Tahmassebi (2012) in their study of the attitudes of children and their parents towards the attire of student dentists, found that children preferred casual attire. ${ }^{10}$

Other studies have reported similar results concerning the expectations of patients of white lab coats and general attire as measures of professionalism. ${ }^{10,11} \mathrm{~A}$ study performed in the United States of America on ten academic centres found that the white lab coat remained the most favourable choice of attire. In addition to dress code, the research found that patients preferred their dentists to have good teeth themselves. ${ }^{11}$

Empathy, initiative, and organizational skills are also considered ideal professional attributes. ${ }^{12}$ Zijlstra-Shaw et al (2013) showed that behaviours like trustworthiness and awareness of others are essential in dealing with patients. ${ }^{13}$ The behaviours that people perceive as professional are those that confer trust and reliability. ${ }^{12,13}$ In addition, non-verbal communication is of the utmost importance regarding its effect on first impressions and interpersonal relationships. ${ }^{14}$

This study aimed to assess the perceptions of patients of the professionalism of dental students at a South African Tertiary Oral Health Centre (SA-OHC).

\section{METHODS}

A cross-sectional analytical study was performed on new and booked patients to yield information regarding perceptions of the professionalism of students. The study site was a tertiary teaching hospital located in the central business district of the city and patients either walk in for services or are referred by secondary and primary oral care centres. The study participants, aged 18 years and above, were recruited over a period of six weeks and all patients who agreed to participate formed the study sample.

Following ethical recruitment and granting of written informed consent, patients were then interviewed after they received treatment in one of the five dental school clinics. These included maxillofacial and oral surgery, periodontology, prosthodontics, oral rehabilitation, oral hygiene and radiology. The wide selection of clinics enabled a broader view of the patients, as well as of the students. The Human Research Ethics Committee granted permission (ethical clearance number M160101).

The dental students managing patients during data collection were not aware of the study. The hospital management was informed when data collection was in process. Interviews were based on an adapted questionnaire by Brosky and colleagues in $2003 .^{3}$ The 17-item questionnaire comprised of socio-demographic data, physical appearance, behaviour, attitude and communication skills. A five-point Likert scale $(1=$ strongly disagree, 2 = disagree, $3=$ neutral, $4=$ agree and $5=$ strongly agree.) was used to rate the students on their behaviour, and their interpersonal and physical appearance. Additionally, patients were required to identify, without references, which outfits they deemed most professional from pictures, none of which announced professionalism.

\section{Data analysis}

The data from the questionnaires were captured on Microsoft Excel, exported to Stata version 13 and the Shapiro-Wilk $W$ test was used to test for normality. Univariate descriptors such as socio-demographics were summarised using means and medians for skewed data. Bivariate analysis; chi-squared tests and Fischer Exact Test were used to determine the significances of differences between groups.

Preliminary analysis showed only a few options selecting scores 1 and 5. The categories "strongly agree" and "agree" were then combined to form the category "agree", and the categories "strongly disagree" and "disagree" were combined to form the category "disagree". Thus, three categories of responses (agree, neutral and disagree) were used in the results. Binary logistic regression was performed to analyse the predictors of the perceptions of the patients.

\begin{tabular}{|c|c|c|c|}
\hline Characteristic & & Frequency & Percentage \\
\hline $\begin{array}{l}\text { Age } \\
\text { (mean; SD) }\end{array}$ & $\begin{array}{l}44 \text { years } \\
\text { SD }-18.16\end{array}$ & & \\
\hline \multicolumn{4}{|c|}{ Age categories } \\
\hline & $19-30$ years & 39 & 33.05 \\
\hline & $31-40$ years & 18 & 15.25 \\
\hline & $41-50$ years & 14 & 11.86 \\
\hline & $51-60$ years & 21 & 17.80 \\
\hline & $>60$ years & 26 & 22.03 \\
\hline \multicolumn{4}{|l|}{ Sex } \\
\hline & Male & 33 & 27.97 \\
\hline & Female & 85 & 72.03 \\
\hline \multicolumn{4}{|c|}{ Home language } \\
\hline & English & 54 & 45.76 \\
\hline & Sesotho (all) & 12 & 10.17 \\
\hline & isiZulu & 26 & 22.03 \\
\hline & isiXhosa & 6 & 5.08 \\
\hline & Afrikaans & 8 & 6.78 \\
\hline & Other & 12 & 10.17 \\
\hline \multicolumn{4}{|c|}{ Classification of patients by individual income } \\
\hline & $\begin{array}{l}\text { HO: } \\
\text { Pensioner }\end{array}$ & 28 & 24.78 \\
\hline & $\begin{array}{l}\text { H1: } \\
\text { RO - } 35999 \text { p/a }\end{array}$ & 68 & 60.18 \\
\hline & $\begin{array}{l}\text { H2: R36000 - } \\
\text { R71999 p/a }\end{array}$ & 9 & 7.96 \\
\hline & $\begin{array}{l}\text { H3: } \\
\text { > R80000 p/a }\end{array}$ & 7 & 6.19 \\
\hline & Private & 1 & 0.88 \\
\hline \multicolumn{4}{|c|}{ Patients' education level } \\
\hline & Primary school & 30 & 25.42 \\
\hline & Matric & 42 & 44.92 \\
\hline & In-training & 13 & 11.02 \\
\hline & $\begin{array}{l}\text { Tertiary } \\
\text { education }\end{array}$ & 33 & 27.97 \\
\hline \multicolumn{4}{|c|}{ Patient appointment status } \\
\hline & Booked patient & 76 & 64.96 \\
\hline & New patient & 41 & 35.04 \\
\hline
\end{tabular}




\section{RESULTS}

\section{Socio-demographics}

A total of 118 patients responded to the invitations to the interviews; their mean age was 44 years (SD-18.16) with an age range of 19-82 years. Other socio-demographic characteristics are described in Table 1.

Seventy-seven (65\%) were patients who had had prior visit/s to the facility and were thus booked for dental appointments whilst $(n=41) 35 \%$ were first time users of the facility. Ninety-two percent of the patients were treated by dental students and the remaining eight percent were treated by oral hygiene students.

\section{Patient perceptions}

The perceptions of the patients regarding the physical appearance, behaviour and communication skills of students were assessed. The questionnaire showed good internal consistency with a Cronbach-alpha of 0.7.

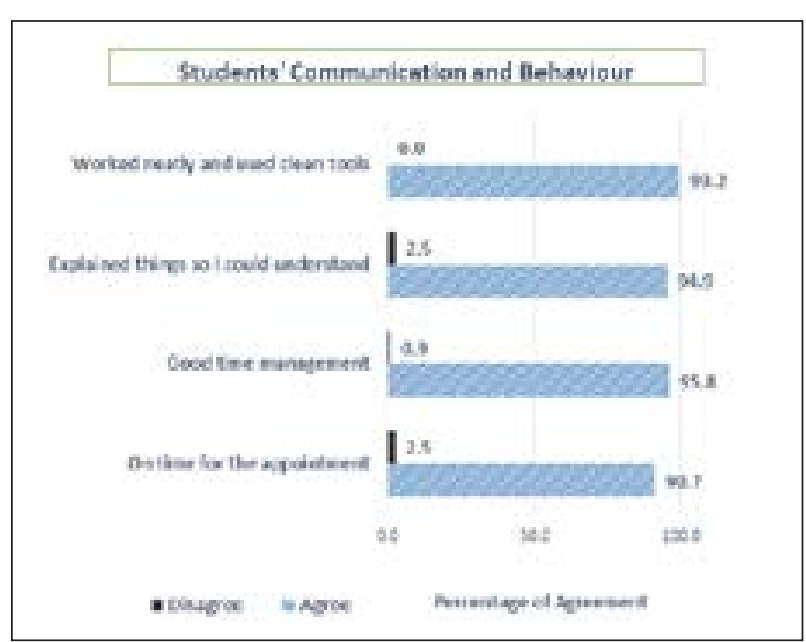

Figure 1. The students' behaviour and communication skills.

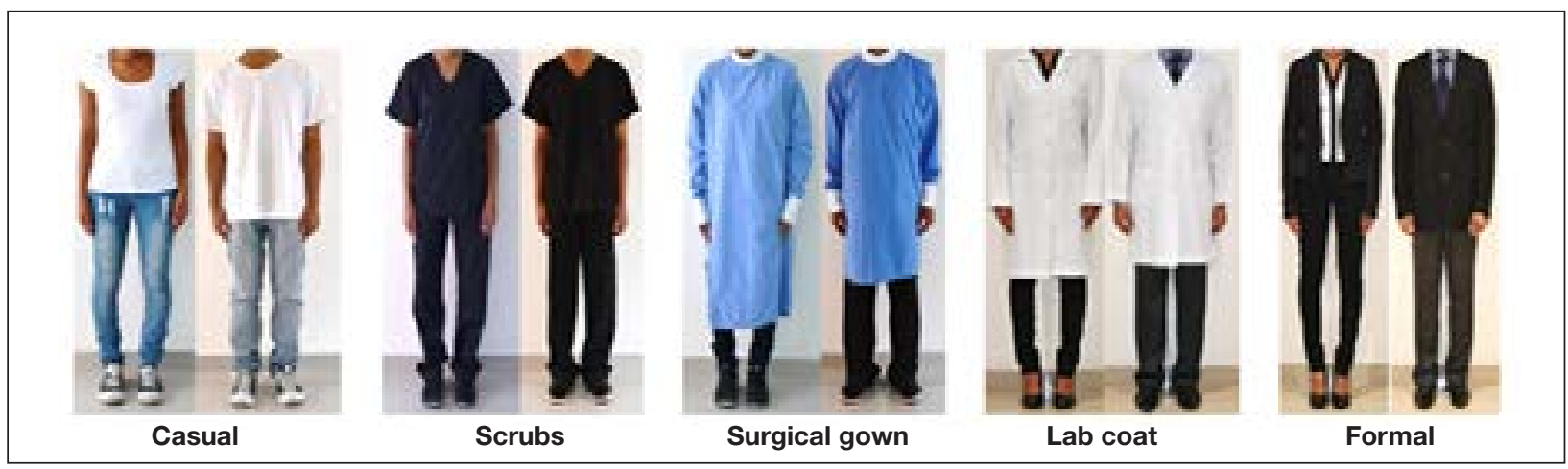

Figure 2. Photographs used for ranking of professionalism by patients.

\begin{tabular}{|c|c|c|c|c|c|c|}
\hline \multirow[t]{2}{*}{ Physical appearance items and responses } & \multicolumn{2}{|c|}{ Disagree } & \multicolumn{2}{|c|}{ Neutral } & \multicolumn{2}{|c|}{ Agree } \\
\hline & $\mathbf{n}$ & $\%$ & $\mathbf{n}$ & $\%$ & $\mathbf{n}$ & $\%$ \\
\hline 1. I believe the dental student looked professional & 4 & 3.9 & 1 & 0.85 & 113 & 95.76 \\
\hline $\begin{array}{l}\text { 2. Dental students should wear a white lab coat rather than surgical } \\
\text { gowns or scrubs }\end{array}$ & 57 & 48.31 & 29 & 24.58 & 32 & 27.12 \\
\hline 3. The student's hairstyle affected my confidence in him/her & 92 & 77.97 & 7 & 5.93 & 19 & 16.10 \\
\hline 4. The student's facial hair and/or makeup affected my confidence in him/her & 97 & 82.91 & 5 & 4.27 & 15 & 12.82 \\
\hline 5. The student's jewelry affected my confidence in him/her & 97 & 82.91 & 13 & 11.11 & 7 & 5.98 \\
\hline $\begin{array}{l}\text { 6. Formal clothes (trousers, collared shirts, skirts and blouses) should be } \\
\text { required for dental students }\end{array}$ & 65 & 55.08 & 19 & 16.10 & 34 & 25.81 \\
\hline $\begin{array}{l}\text { 7. Casual clothes (takkies, jeans, t-shirts) should be allowed for } \\
\text { dental students }\end{array}$ & 54 & 45.76 & 10 & 8.47 & 54 & 45.76 \\
\hline 8. All jeans should be considered casual & 37 & 31.62 & 13 & 11.11 & 67 & 57.26 \\
\hline $\begin{array}{l}\text { 9. The dental student's appearance/clothing changed my feelings about the } \\
\text { care I will receive in the future }\end{array}$ & 86 & 72.88 & 8 & 6.78 & 24 & 20.34 \\
\hline 10. The dental student's appearance/clothing changed how comfortable I felt & 73 & 61.86 & 8 & 6.78 & 37 & 31.36 \\
\hline 11. The dental student's appearance/clothing changed how scared I felt & 92 & 77.97 & 10 & 8.47 & 16 & 13.55 \\
\hline 12. My confidence in the dental student was affected when I first saw them & 73 & 61.87 & 5 & 4.24 & 40 & 33.9 \\
\hline
\end{tabular}


The students were generally perceived positively by patients in most aspects. As regards the physical appearance of students (Table 2), 96 percent of the patients agreed that the students looked professional.

Almost half of the patients (48\%) voted against students wearing a white labcoat instead of surgical gowns or scrubs, while a quarter remained neutral. In addition, about a third (34\%) of patients reported that their 'confidence in the dental student was affected when I first saw them'.

Student communications and behaviour skills were highly rated by patients, 95-99 percent agreeing that the students displayed good attributes in these categories (Figure 1).

The working attire of students was assessed by requesting patients to rank their preferences of different clothing depicted in photographs (Figure 2).

Figure 3 records that $80 \%$ of the patients considered lab coats as the most professional with surgical gowns considered the second (56\%) while scrubs were held to be a third choice in professionalism (36\%).

It may have been expected that casual wear would be considered by patients to be the least professional, $91 \%$ of whom did record that opinion, However, it was unexpected that formal smart wear would also be dismissed as hardly professional (69\%).

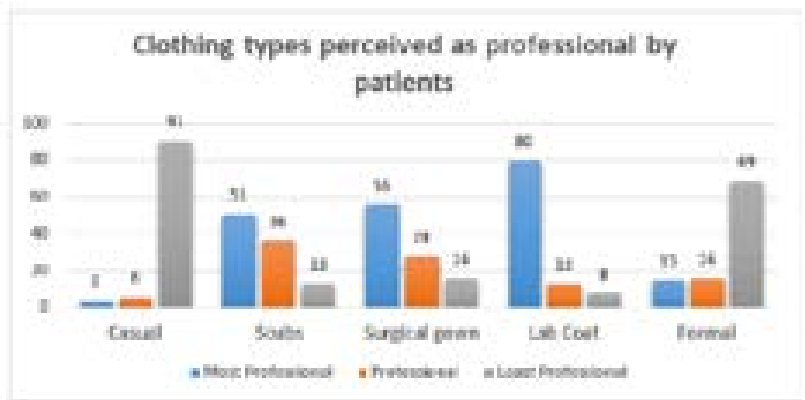

Figure 3. Clothing types perceived as professional by patients.

\section{Factors influencing the patients' perceptions}

The characteristics of patients influenced their perceptions of the professionalism of students. Factors such as household income, which determined which category of fee schedule was applied, was associated with the choice of lab coat versus surgical gown $(p=0.05)$.

Those patients with lower income (categories $\mathrm{HO}$ and $\mathrm{H} 1$ ) preferred lab coats rather than surgical gowns. All hospital users are also routinely categorized according to race. The study found that black African patients preferred students to wear lab coats rather than surgical gowns.

Sex was another factor that influenced perceptions; female patients thought scrubs were more professional than did male patients $(p=0.05)$. The younger age group were more inclined than the older age group of patients to prefer scrubs. Race was also associated with the perception of formal wear being not professional $(p=0.02)$; most black Africans thought it the least professional.

\section{DISCUSSION}

The study aimed to assess professionalism of dental students from the perspectives of the users of the health facility at a Tertiary Teaching Oral Health Centre.

Student training entails the teaching of professionalism and more often assessment and evaluation of professionalism is based on the content of the teaching module and the context of practice by the teaching staff. It is advantageous to have input from the patients in order to indirectly assess the standard of teaching. As an add-on, the assessment provides feedback about quality assurance for provision of services.

The demographics of the patients were typical of public facility users where the majority are female $(72 \%)$, and of a lower income category with \pm R3000p.m (85\%); but the distribution was atypical in South African public utilization, for nearly half of the users (47\%) were non-black patients. In the nationally representative household survey, Harris et al (2011) reported an $80 \%$ utilization by black Africans of the public health facilities in South Africa. ${ }^{15}$

Perceptions of the professionalism of dental students were measured by their attire and physical appearance, behaviour and communication skills. The students' physical appearance was rated exceptionally high by patients, as $96 \%$ favourable. These results are comparable with a study on patient perceptions of professionalism in Dentistry at a university in Minnesota, America; the findings reported that $94 \%$ of patients agreed that students were $^{\text {professional. }}{ }^{3}$

However, Brosky and co-authors (2013) reported the opposite when their sample were asked whether the dental student's appearance/clothing 'changed my feelings about the care I will receive in the future.' About $80 \%$ of those patients agreed that appearance affected their feelings regarding care. In contrast, $74 \%$ disagreed with that reaction in the current study. ${ }^{3}$

The patients in this study seemed not to be worried by physical features such as hairstyle, facial hair, makeup and jewelry. None of these considerations affected their confidence in the student nor influenced the degree of anxiety they experienced (Table 2).

Dress code is an important part of physical appearance. A 2007 study in Edinburgh on patient preferences for dental clinical attire found that $62 \%$ of patients agreed it is important, and ${ }^{16} 76 \%$ of participants preferred white coats. ${ }^{16}$

Other investigators concur. ${ }^{7,8,10,11}$ Only $27 \%$ of the patients in the study under report agreed that students should wear a white lab coat in preference to scrubs or surgical gowns, whilst $24 \%$ remained ambivalent.

Perspectives on attire were also influenced by whether children or adults were responding. Findings from the Paediatric Dental Department in Leeds, UK, revealed that parents opted for commonly expected attire like white coats, formal suits and shirts and tie, and yet the children preferred the dental students to be in casual attire. ${ }^{10}$ 
Likewise, it was expected in the current study for patients to prefer a more formal appearance, as seen in papers by other authors. ${ }^{3,9,16}$ Instead, it was found that $55 \%$ of patients disagreed that students should be required to wear formal clothes. In fact, in the photographic ranking, forma I wear was considered most professional by only $15 \%$ of patients. Time trends and context seem to surface in the modern day preference for professional dress code. ${ }^{13}$ It seems the users of the facility in the current study are still conservative which, together with income levels, influenced the preference of the traditional white coat over other forms of wear.

However, there did appear to be a leaning towards 'change in looks' as approximately a third preferred a relaxed scrub look as opposed to the traditionally crisp clean white coat. The evidence, admittedly weak, suggests a modern-day trend which may be influenced by the media and the portrayal of health professionals in ready and comfortable attire. This trend will accommodate a more relaxed, scrubs wearing-look in the workplace. However, relaxed does not mean casual attire, as patients still prefer the 'official' relaxed look in the form of scrubs as opposed to casual clothes, ranked significantly most unprofessional. Younger age groups in the study preferred scrubs to lab coats in echoing the current social-media sentiment accessible to mostly young people. Female patients were more inclined to prefer a 'scrub look,' shown in this and other studies. ${ }^{16}$ Perhaps females are more accommodating and accepting of the new.

Behavioural and communication aspects included punctuality, time management during appointments, communicating and explanation of treatment modalities to patients, as well as cleanliness of the work space and of instruments used during appointments. The students in the current were rated exceptionally highly at $91-99 \%$ on all those aspects. Brosky et al had similar results, with the majority of patients agreeing to behavioural and communicative aspects of the practitioners. ${ }^{3}$ The current findings provide an external evaluation of the training institution at this Dental School. The Institute imposes stringent training of students, especially with regards to infection control and time management. The assessment of students is linked to these competencies which encourage the practice of professionalism for the future. This is a positive feedback for this important exit level competency.

\section{Limitations}

The cross-sectional nature of the study and low sample numbers may have limitations. A larger sample would have made it possible to improve the statistical margin of error.

\section{CONCLUSIONS AND RECOMMENDATIONS}

Despite the limitations, the current study gave insights on the way in which students are perceived by the patients at the Tertiary Training Oral Care Centre. The results provide an important feedback to the training institution. Specifically, the results have implications for the professionals qualifying from the training institution. The dynamic nature of professionalism and the fact that context can shape the practice and conduct of professionals are highlighted; professionalism does not function in a vacuum. It is recommended that policies related to dress codes should be dynamic and should accommodate the perspectives of patients, including the student's comfort, professional look, infection control concerns and overall better quality of service delivery. A users' awareness programme on the reasons behind the preferences for specific attire such as scrubs will serve to explain the concepts of professionalism and may lead to enhanced confidence in the profession.

\section{Acknowledgements}

We would like to thank the Head of the Community Dentistry Department, Prof Yengopal, the School of Oral Health Sciences and the Wits Oral Health Centre for support, the opportunity and the space to conduct this research project.

\section{References}

1. Dhai A. Understanding professionalism in health care in the twenty-first century. South African Dental Journal 2008; 63(3):174-7.

2. HPCSA. Guidelines for good practice in the health care professions. General Ethical Guidelines for the Health Care Professions. Health Professions Council of South Africa, 2013.

3. Brosky ME, Keefer OA, Hodges JS, Pesun IJ, Cook G. Patient perceptions of professionalism in dentistry. Journal of Dental Education 2003;67(8):909-15

4. Barondess JA. Medicine and professionalism. Archives of Internal Medicine 2003;163(2):145-9.

5. Bersheid E, Gangestad S. The social psychological implications of facial physical attractiveness. Clin Plast Surg. 1982; 9(3):289-96.

6. Newton T, Asimakopoulou K, Daly B, Scambler S, Scott S. The management of dental anxiety: time for a sense of proportion? British Dental Journal 2012;213(6):271-4.

7. Furnham A, Chan PS, Wilson E. What to wear? The influence of attire on the perceived professionalism of dentists and lawyers. Journal of Applied Social Psychology 2013;43(9):1838-50.

8. Deshmukh S, Sharma, A, Soni, V, Thombare, P, Tiberewal, $H$, Lavankar A. Should Dentists wear a white coat or not? A cross-sectional study. IOSR Journal of Dental and Medical Sciences 2013;10(1):4.

9. Kanzler $\mathrm{MH}$, Gorsulowsky DC. Patients' attitudes regarding physical characteristics of medical care providers in dermatologic practices. Archives of Dermatology 2002;138(4):463-6.

10. Mistry D, Waddington TJ. Children's and parents' attitudes towards dentists' attire. European Archives of Paediatric Dentistry 2009;10(4):237-40.

11. Petrilli CM, Saint S, Jennings JJ, Caruso A, Kuhn L, Snyder $A$, et al. Understanding patient preference for physician attire: a cross-sectional observational study of 10 academic medical centres in the USA. British Medical Journal open 2018;8(5):e021239.

12. Kasar J, Clark EN. Developing Professional Behaviours. NJ, USA: Slack Incorporated; 2000.

13. Zijlstra-Shaw S, Roberts T, Robinson P. Perceptions of professionalism in dentistry-a qualitative study. British Dental Journal 2013;215(9):E18.

14. Lovas JG, Lovas, DA, Lovas PM. Mindfulness and professionalism in dentistry. Journal of Dental Education 2008;72(9):998-1009.

15. Harris B, Goudge J, Ataguba JE, Mclntyre D, Nxumalo N, Jikwana $S$, et al. Inequities in access to health care in South Africa. Journal of Public Health Policy 2011;32(1):S102-S23.

16. McKenna G, Lillywhite G, Maini N. Patient preferences for dental clinical attire: a cross-sectional survey in a dental hospital. British Dental Journal 2007;203(12):681-5. 